\title{
Two Stamped Amphora Handles from Tel Zeror in the Tenri University Sankokan Museum ${ }^{1}$
}

\author{
Shuichi HASEGAWA*
}

Two of the Rhodian amphora handles uncovered by the Japanese Expedition at Tel Zeror in 1964-1966 are now located in the Tenri University Sankokan Museum, Tenri, Japan. They were both excavated on the northern mound of Tel Zeror, which was inhabited during the Hellenistic and Roman Periods. They can be dated to the early and midsecond century BCE on the basis of the readings of the eponym/fabricant names on the stamps. The dates are paralleled with one of the three chronologically successive buildings uncovered on the northern mound. The date of the amphorae and the location of the site support the view that Tel Zeror functioned as one of the main stations between the Mediterranean and Samaria in the mid-second century BCE.

Keywords: Rhodian amphora, Tel Zeror, Tenri Sankokan Museum, Hellenistic Period, Sharon Plain

\section{Introduction}

During the excavations at Tel Zeror (Map ref. NIG 197600/703800; OIG 147600/203800) in the Sharon Plain in 1964-1966 and 1974, several stamped Hellenistic amphora handles were unearthed. ${ }^{2}$ Two of them, both Rhodian, were transferred to Japan under an agreement between the Japanese Expedition and Israel Antiquities Authority, and are now located in the Tenri University Sankokan Museum, Tenri, Japan. ${ }^{3}$ These amphora handles were omitted from preliminary reports of the Tel Zeror Excavations.

Systematic studies on Rhodian amphorae have continued, in particular from the 1980s onward, with the accumulation of new material and subsequent compilation of Rhodian amphora catalogues in the last three decades. Amongst all, the studies of V. R. Grace and J.-Y. Empereur established a relative chronology of Rhodian amphorae and advanced their value as a chronological anchor in excavations. ${ }^{4}$ With G. Finkielsztejn's recent studies, our understanding of both relative and absolute chronologies of Rhodian amphora stamps entered a new phase. ${ }^{5}$ Revising the conventional criteria, he suggested a

* Ph.D. Student, Department of Jewish History, Tel Aviv University 
thorough and more precise chronology of Rhodian amphorae from 280 to 108 BCE. In light of recent advancement in chronological research on Rhodian amphorae, this paper aims at exhibiting the two stamped amphora handles and giving their readings and possible dates, in order to illuminate the history of Tel Zeror in the Hellenistic Period. Note, that for convenience, the low-chronology recently suggested by Finkielsztejn, and the conventional chronology by Grace will be juxtaposed in dating the eponym and the fabricant. ${ }^{6}$

\section{Catalogue of Amphora Handles}

1. Inventory number TZ 47/2003A61 (Fig. 1).

Round die (approximately $3.2 \mathrm{~cm}$ in diameter) with rose in the centre, retrograde. The handle is about $9.8 \mathrm{~cm}$ long; hue 7.5YR 7/3 (Dull Orange); well-levigated with regular firing.

Provenance: Area A, Squares RS18-20, surface layer. ${ }^{7}$
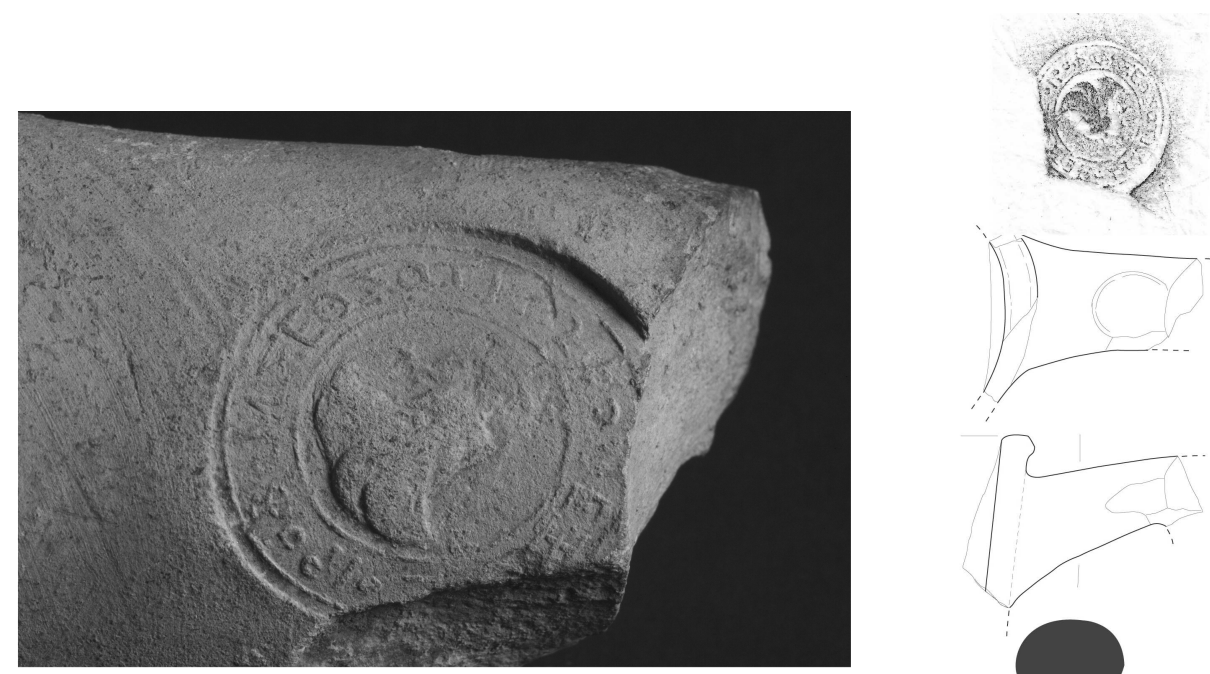

Fig. 1 2003A61 (C Haruo Nakano)

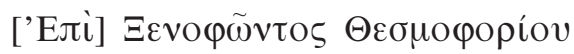

The Rhodian eponym $\Xi \varepsilon v o \varphi \tilde{\omega} v$ is dated by Finkielsztejn to $c$. $164 / 162$ BCE (Period IIIe), ${ }^{8}$ and to $182-176$ BCE by Grace. ${ }^{9}$ Stamps bearing his name have been unearthed in wide range of regions, but were mainly distributed over the 
Aegean islands and coasts as well as over southern Levant. ${ }^{10}$

2. Inventory number TZ 184/2003A121 (Fig. 2).

Rectangular die (approximately $3.8 \times 1.4 \mathrm{~cm}$ ), poorly preserved. The handle is $9.5 \mathrm{~cm}$ long; hue 7.5YR 7/3 (Dull Orange); well-levigated and regular firing.

Provenance: Area A, Square T20, Locus $10 .{ }^{11}$

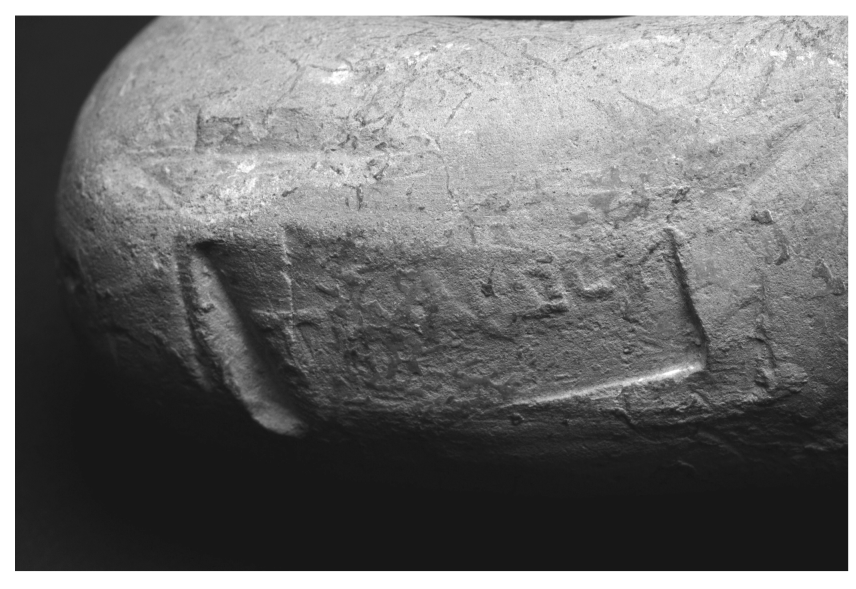

Fig. 2 2003A121 (C) Haruo Nakano)
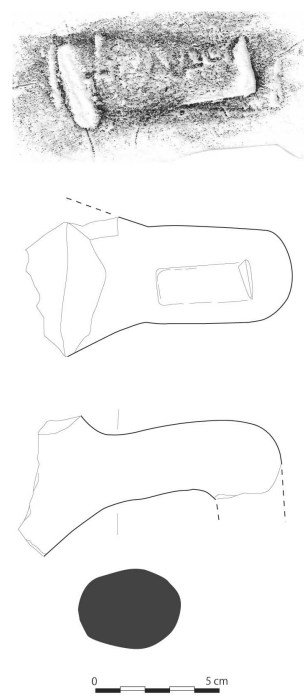

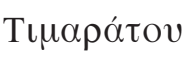

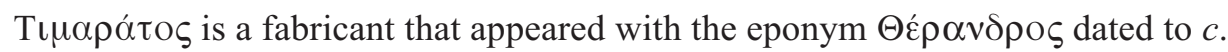
137/136 BCE by Finkielsztejn ${ }^{12}$ and to $141-135$ BCE by Grace. ${ }^{13}$ Stamps bearing this name were found mainly in Egypt and in Rhodes, and only one example is known in southern Levant. ${ }^{14}$

\section{Discussion}

Both stamps date to the mid-second century BCE, after the Seleucid victory over the Ptolemies in the Fifth Syrian War (ca. 202-198 BCE), which secured the former's dominion over southern Levant. Rhodian amphorae dating to this period have been found throughout southern Levant, ${ }^{15}$ providing evidence for the Seleucid commercial relationship with the island. The Seleucid rule over the region was shaken after the Maccabean Revolt in 167 BCE. However, the Northern Sharon Plain, where Tel Zeror is located, was not captured by the Jews 


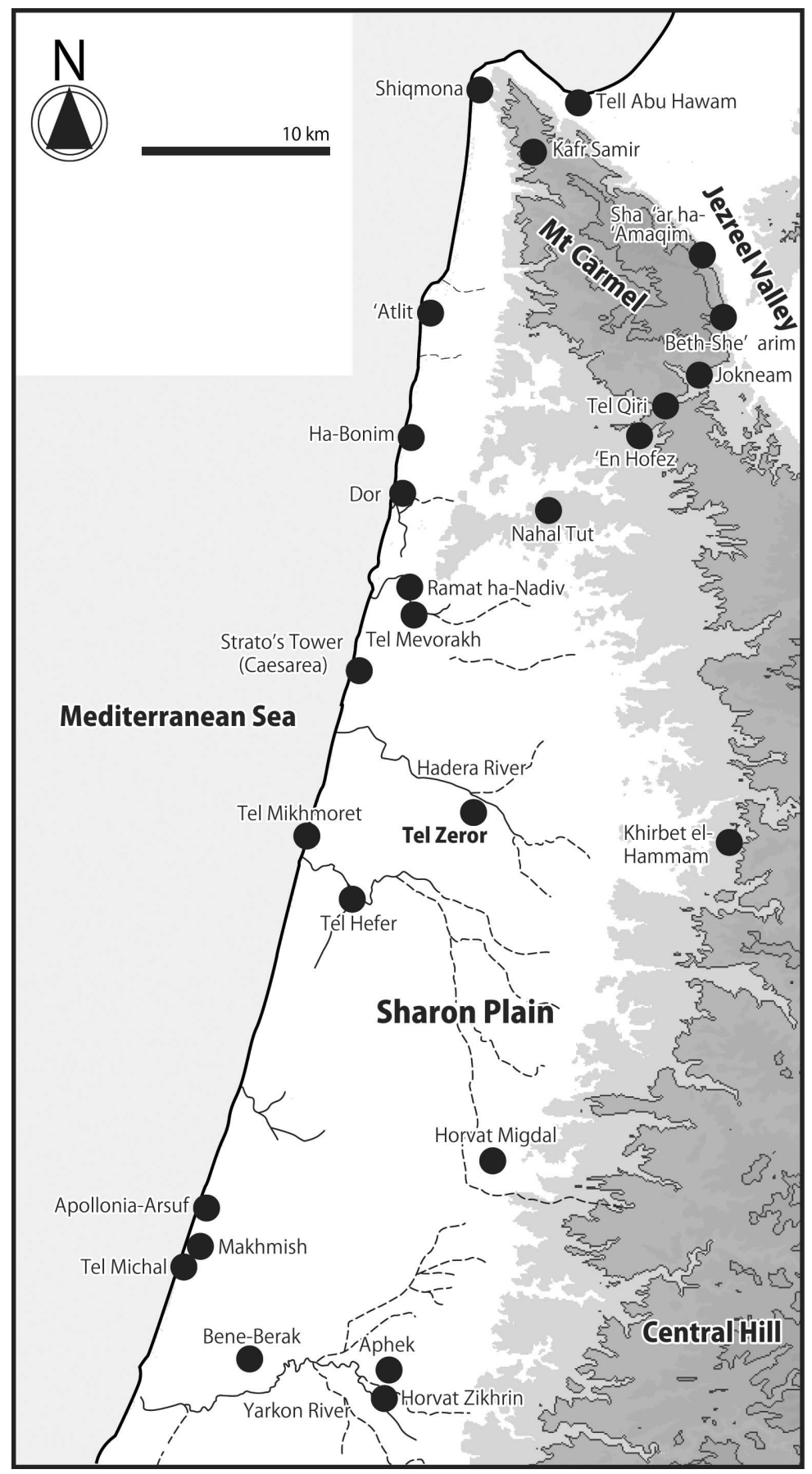

Fig. 3 Sharon Plain in the Hellenistic Period 
until Alexander-Jannaeus's conquest of the region dated to $c a 100$ BCE (Fig. 3). The site was probably settled by a Phoenician population as in Dor and at "Strato's Tower" (Caesarea in the Roman Period) throughout this tumultuous century.

The Hellenistic settlement at Tel Zeror was limited to the northern mound. Stone foundations of three chronologically-successive buildings were uncovered in the area. H. Ogawa designated these buildings as Towers A, B, and C, of which Tower $\mathrm{C}$ was the earliest. ${ }^{16}$ Only tower B was fully excavated $(12.6 \times 10$ $\mathrm{m})$ but it is clear that they all have similar rectangular plans. He suggested that Tower C was destroyed by Alexander-Jannaeus around 100 BCE. ${ }^{17}$ Hellenistic coins from the related loci date from the mid-third century to the early half of the second century BCE. ${ }^{18}$ Some amphora handles were uncovered inside a pit sealed by the floor of Tower B, one of which dates to the early half of the second century BCE. ${ }^{19}$ The second stamp in this article, which was also found in the north-western room of Tower A, falls within this time-span.

Neither the route of the amphorae transported from Rhodes to Tel Zeror nor the harbour of their discharge can be determined. Strato's Tower and Tel Mikhmoret ${ }^{20}$ are two possible candidates for the port of discharge, the latter of which is located only about nine kilometres west of Tel Zeror and was constantly inhabited throughout the Hellenistic period. Samaria, about twentyfive kilometres southeast of Tel Zeror, also flourished in the Hellenistic Period. ${ }^{21}$ Considering its geographical location between the Mediterranean and Samaria, it seems reasonable to assume that Tel Zeror served as one of the stations between the two places for transporting commodities, including amphorae.

\section{Notes}

1 This article is dedicated to the memory of the late Professor Moshe Kochavi.

2 The first three seasons of the excavation were conducted by the Society for Near Eastern Studies in Japan and was directed by K. Ohata (1964-1966) with the support of Israeli archaeologists, among whom the late M. Kochavi worked as the field director. K. Ohata, Tel Zeror I: Preliminary Report of the Excavation, First Season 1964, Tokyo, 1966; Tel Zeror II: Preliminary Report of the Excavation, Second Season 1965, Tokyo, 1967; Tel Zeror III: Preliminary Report of the Excavation, Third Season 1966, Tokyo, 1970. Exact numbers of the amphora stamps unearthed at Tel Zeror are unfortunately unknown. The rest of the stamps, which should be located in the storehouse of the Israel Antiquities Authority, could not be located during my visit to the storehouse in July 2009.

${ }^{3}$ My thanks go to Y. Tatsumi and Y. Iburi of the Tenri Sankokan Museum, who kindly assisted me in studying the Amphora stamps during my stay in the Museum. The study travel was financially supported by the Ohata Grant for the History of Religion (Grantee: N. Yamauchi). I wish to express my gratitude to the grantee.

4 V. R. Grace, "The Middle Stoa Dated by Amphora Stamps," Hesperia 54 (1985), 1-54; J.-Y.

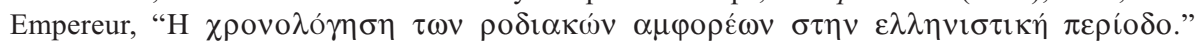

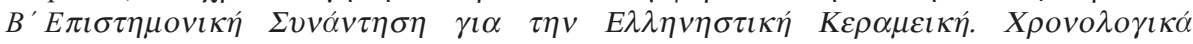




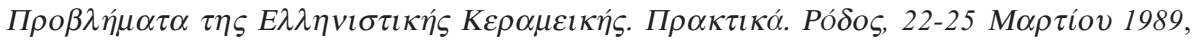
Athens, 1990, 199-209.

${ }^{5}$ G. Finkielsztejn, Chronologie détaillée et révisée des eponyms amphoriques rhodiens, de 270 à 108 av. J.-C. environ, BAR International Series 990, Oxford, 2001.

${ }^{6}$ Finkielsztejn's chronology based on his thorough and up-dated study of the material seems to me preferable.

7 Basket Number 858, Aug 15, 1965.

${ }^{8}$ Finkielsztejn, op. cit., 192.

${ }^{9}$ Grace, op. cit., 8-9.

${ }^{10}$ The following data was collected from excavation reports made available to the author at the time of writing this paper. First comes the name of the site, secondly in parenthesis is the name of the region followed by a number of examples. Lindos and Nea Paphos (Rhodes: 11); Delos (Aegean island: 3); Athens (Greek mainland: 1); Pergamon (Anatolian Aegean coast: 5); Samaria, Jerusalem, Tell Keisan, and Khirbet el-'Uyun (southern Levant: 12); Beyrouth (northern Levant: 2); Akoris, Crocodilopolis-Arsinoe, and Milne (Egypt: 3); Carthage (north Africa: 1).

${ }^{11}$ Basket Number 144/1, Jul 24, 1964. The register noted that it might have originated "from the foundation trench".

12 S. J. Monachov, "Rhodian Amphoras: Developments in Form and Measurements," in V. F. Stolba and L. Hannestad (eds.), Chronologies of the Black Sea Area in the Period c. 400-100 $B C$, Black Sea Studies 3, Aarhus, 2005, 84, fig. 7:1; Finkielsztejn, op. cit., 50, n. 67, 195.

13 Grace, op. cit., 13, n. 24.

14 The following data contains examples from museums in a variety of regions. The origin of the examples cannot be determined so they are listed according to the location of the museum. Lindos, Nea Paphos, and another unknown place (Rhodes: 5); Delos (Aegean island: 1); KitionBamboula and other unknown places (Cyprus: 3); Halicarnassus (Anatolian Aegean coast: 1); Akoris and other unknown places (Egypt: 10); Sicily (western Mediterranean: 1); Tel MareshaMarissa (southern Levant: 1).

15 The chronological distribution of these handles must be examined in order to provide comparable data. Such data is available for the City of David and Tell Keisan (D. T. Ariel, "Imported Stamped Amphora Handles," in D. T. Ariel, Excavations at the City of David 19781985 Directed by Yigal Shiloh, Volume II: Imported Stamped Amphora Handles, Coins, Worked Bone and Ivory, and Glass, Qedem 30, Jerusalem, 1990, 20, Tab. 2). It demonstrates that the number of the Rhodian amphora handles reached its peak during Period III and remarkably declines after Period IV. The distribution generally conforms to that of the Rhodian stamped amphora handles found in Rhodes (Finkielsztejn, op. cit., 202, fig. 2.).

${ }^{16}$ H. Ogawa, "Hellenistic and Roman Towers on the North Rise, Tel Zeror," Orient 20 (1984), 109. According to him, Tower B is the latest of the three and Tower A is the earlier phase of Tower B.

${ }^{17}$ Ogawa, op. cit., 116.

18 Two Hellenistic coins, those of Ptolemy II (285-246 BCE) and Antiochus III (223-187 BCE) were discovered. Ohata 1965, 3; Ogawa, op. cit., 114.

19 According to Ogawa (op. cit., 113-114), "Jar handles dating the first half of the second century B.C., for example, were recovered from a pit sealed by the floor of Tower B." He (op. cit., 123, n. 7) noted the Coan jar handle with the inscription of "Askrepi sic!" for dating the towers (for this handle, see below). Yet, the area (S17) of discovery seems outside the tower. Cf. Ogawa, op. cit., 110, Fig. 1.

${ }^{20}$ Y. Porah, S. M. Paley, and R. R. Stieglitz, "Mikhmoret, Tel," The New Encyclopedia of Archaeological Excavations in the Holy Land, Vol. 3, 1993, 1043-1046.

${ }^{21}$ G. A. Reisner, C. S. Fisher, and D. G. Lyon, Harvard Excavations at Samaria (1908-1910), Vols. I-II, Cambridge (MA), 1924. Bibliography on Samaria excavations can be found in N. Avigad, "Samaria (City)," The New Encyclopedia of Archaeological Excavations in the Holy Land, Vol. 4, 1993, 1310. 